\title{
Discrete Set Coded String Data Type
}

National Cancer Institute

\section{Source}

National Cancer Institute. Discrete Set Coded String Data Type. NCI Thesaurus. Code C95645.

A data type comprised of a collection of a discrete set of coded string values that are distinct. 